\title{
Is reintroduction a tool for the conservation of the jaguar Panthera onca? A case study in the Brazilian Pantanal
}

\author{
Rose Lilian Gasparini- Morato, Leonardo Sartorello, Lilian Rampim \\ Carlos Eduardo Fragoso, Joares Adenilson May Jr, Pedro Teles \\ Mario Haberfeld, Rogério Cunha de Paula and Ronaldo Gonçalves Morato
}

\begin{abstract}
To evaluate the feasibility of reintroduction as a tool for conservation of the jaguar Panthera onca, we adapted the IUCN soft release protocol to reintroduce two jaguars in the southern Pantanal, Brazil. After being kept at rescue centres for 13 months, the jaguars were moved to a 1-ha enclosure with native vegetation on a 53,000 ha ranch in the Pantanal, where hunting is not allowed and prey is abundant. In the enclosure, the animals were fed with meat, dead animals (roadkill) and then, progressively, live wild prey. After 11 months, the jaguars were fitted with collars equipped with GPS/VHF (recording one location per hour) and accelerometers, and released in the same area. The animals established residence near the enclosure, with home ranges, movement parameters, daily activity patterns and prey consumption similar to that recorded in previous studies. Social interaction and reproduction indicated the reintroduction was successful, and that it can be a tool for the species' survival in areas where the jaguar population is in decline.
\end{abstract}

Keywords Brazil, home range, jaguar, Pantanal, Panthera onca, reintroduction

The historical range of the jaguar Panthera onca has con1 tracted and many populations are now threatened (De la Torre et al., 2017), including the subpopulations in the Atlantic Forest (Morato et al., 2013). The last c. 300 individuals in this forest occur in seven subpopulations, and the

Rose Lilian Gasparini-Morato* (Corresponding author, (D) orcid.org/00000003-2885-0034), Rogério Cunha de Paula (iD orcid.org/0000-0003-19438320) and Ronaldo Gonçalves Morato (iD orcid.org/0000-0002-8304-9779) Instituto Chico Mendes de Conservação da Biodiversidade - Centro Nacional de Pesquisa e Conservação de Mamíferos Carnívoros, Estrada Municipal Hisaichi Takebayashi 8600, 12952-011, Atibaia, São Paulo, Brazil

E-mail rose.morato@icmbio.gov.br

Leonardo Sartorello* (D orcid.org/0000-0001-7607-9577), LiLian Rampim (D) orcid.org/0000-0001-8121-3152), Carlos Eduardo Fragoso (D orcid.org/ 0000-0001-8971-2896), JOARES AdENILSON MAY JR (D orcid.org/0000-00020007-9690), Pedro Teles (iD orcid.org/0000-0003-0754-2470) and Mario Haberfeld (D) orcid.org/0000-0001-9360-6658) Associação Onçafari, São Paulo, Brazil

${ }^{\star}$ Contributed equally

Received 22 October 2019. Revision requested 20 December 2019.

Accepted 19 May 2020. First published online 24 March 2021. survival of the species in this biome will depend on reducing jaguar mortality and reconnecting the subpopulations (Paviolo et al., 2016). However, some of these are isolated and the cost of establishment of suitable corridors may be prohibitive (Paviolo et al., 2016), and alternative strategies, such as supplementation and reintroduction, may be required (Galetti et al., 2013).

Reintroductions of apex predators, including the few attempts to reintroduce jaguars, have generally been poorly documented and measurement of failure or success has been hampered by the lack of prior definition of expected outcomes (Breitenmoser et al., 2001). To evaluate reintroduction as a tool for conservation of the jaguar, we adapted the IUCN (2013) soft release protocol to reintroduce two rescued jaguars in the southern Pantanal, Brazil (Fig. 1). We chose this area based on five criteria: (1) rescued animals were from the same region, (2) knowledge of the species' biology in the Pantanal was available, including for the release site (Cavalcanti \& Gese, 2010), (3) availability of suitable habitat (de Paula et al., 2012), (4) prey availability (Perilli et al., 2016), and (5) acceptance by the local community.

Our expected outcomes were that the two jaguars would: (1) prey on wild species (to evaluate this, we compared the species preyed upon with the reported feeding habits of jaguars in the same area; Perilli et al., 2016), (2) establish residence (establishment of residence may be an indicator of acclimation, and jaguars have resident ranges; Rabinowitz \& Nottingham, 1986), (3) have similar home ranges and movement to those reported for jaguars in the Pantanal (Morato et al., 2016), (4) have daily activity patterns comparable to that of resident jaguars, (5) exhibit social interactions (Kanda et al., 2019), and (6) reproduce.

In June 2014, during the flood season, a female jaguar and her two 3-month old female cubs were forced to seek refuge in an urban area of Corumbá, in the state of Mato Grosso do Sul, in the southern Brazilian Pantanal, climbing a tree c. $2 \mathrm{~m}$ from a house. An attempt to capture the jaguars resulted in the accidental death of the mother. The two orphans were moved to a wildlife rescue centre in Campo Grande, where they spent 9 months. We then moved them to a new facility in São Paulo state, with better infrastructure and minimum contact with people, where they stayed for 4 months. 


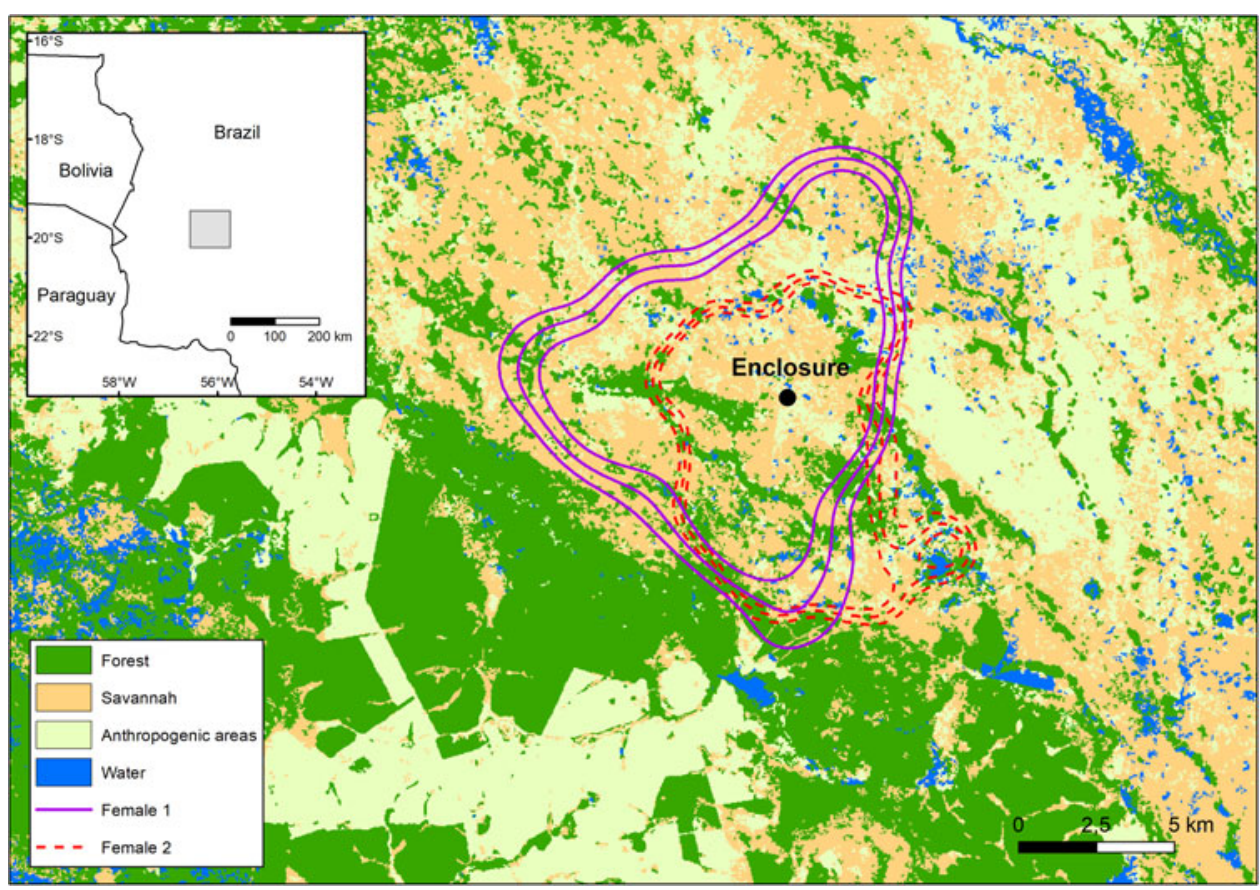

FIG. 1 The estimated home range (with $95 \%$ CI bands) of jaguars Panthera onca 1 and 2 in the southern Pantanal, Brazil. Note the high overlap in their home ranges.
Pre-release, the two jaguars were tested for all relevant infectious and parasitic diseases. At c. 16 months old, having been confirmed healthy, they were moved on 27 July 2015 to a 1 ha enclosure with native vegetation (Plate 1 ) in the Caiman Ecological Refuge, a 53,000 ha private ranch in Miranda, Mato Grosso do Sul (Fig. 1). The ranch is a mixed enterprise, with cattle ranching and ecotourism. It follows jaguar-friendly best practices (Rampim et al., 2020), and hunting is not allowed on the property. As a result, potential prey is abundant and the estimated density of jaguars is c. 7 per $100 \mathrm{~km}^{2}$ (Soisalo \& Cavalcanti, 2006). In the first 2 months in the enclosure the jaguars were fed meat and dead animals (roadkill), to facilitate acclimation. After this, live wild prey was captured and presented, one animal at a time. Prey was released into the enclosure through one of six guillotine gates. These gates were covered with wooden plates to prevent the jaguars associating the arrival of food with people. We observed that hunting was better after 7 days without food. After 11 months the two jaguars were able to chase, surprise and kill all the animals offered. On a few occasions we offered two prey, of the same species, simultaneously, to evaluate hunting behaviour. In total, the jaguars captured and consumed 46 prey, including whitelipped peccaries Tayassu pecari, capybaras Hydrochoerus hydrochaeris, caimans Caiman yacare and feral pigs Sus scrofa scrofa (Table 1). After fitting collars equipped with GPS/VHF, recording one location per hour, and accelerometers, the jaguars were monitored for 30 days inside the enclosure, to provide baseline data on activity patterns and social behaviour.

The two jaguars were released at c. 27 months old, on 9 June 2016. To evaluate movement behaviour and estimate home range and spatial overlap, we used 16 months of telemetry data (June 2016-September 2017). We also performed visual appraisals using images captured by a c. $200 \mathrm{~km}^{2}$ grid of 60 camera traps. We observed that jaguar no. 2 suffered initial loss of weight but recovered 20 days after release. The enclosure door remained open for 3 months and both jaguars returned several times. We fitted a continuous-time stochastic movement model (ctmm; Calabrese et al., 2016) in $R$ 3.5.1 ( $\mathrm{R}$ Core Team, 2018) to evaluate movement behaviour and estimate home range. This method accounts for the inherent serial autocorrelation of our data and could handle irregularities in the sample schedule (Fleming et al., 2015). Range residence behaviour was checked by visual inspection of a semi-variogram (function variogram in $R$ ). Movement models were fit with maximum likelihood (function ctmm. fit) and ranked based on the Aikake information criteria (function ctmm.select). We estimated home range conditional on the fitted model for both individuals using the akde function (autocorrelated kernel density estimator). We estimated spatial overlap using the overlap function. Daily activity patterns were evaluated using Activity Pattern Software (Lotek, Newmarket, Canada) after recovering the accelerometer data from the GPS collars.

We adapted the method described by Cavalcanti \& Gese (2010) to identify prey consumed. When $>4$ consecutive locations were found $<100 \mathrm{~m}$ from each other this was classified as a kill site, where we then searched for prey remains to identify the species. Social behaviour, interactions and reproduction were investigated by observation and cameratrap images. Range residence was confirmed after visual inspection of a semi-variogram, 2 months post release (Morato et al., 2016). Home range estimates were $97.6 \mathrm{~km}^{2}$ 
TABLE 1 Total amount of meat consumed and dead and live prey offered to the two female jaguars Panthera onca during 238 days in an enclosure in the Caiman Ecological Refuge, in Miranda, Mato Grosso do Sul, Brazil.

\begin{tabular}{lc}
\hline & $\begin{array}{l}\mathrm{kg} \text { (no. of } \\
\text { carcasses/individuals) }\end{array}$ \\
\hline Meat & \\
Beef & 137 \\
Chicken & 118 \\
Pig & 13 \\
Dead prey & \\
Capybara Hydrochoerus hydrochaeris & $55(2)$ \\
Giant anteater Myrmecophaga trydactila & $30(1)$ \\
Caiman Caiman yacare & $23(1)$ \\
Live prey & \\
Capybara & $400(15)$ \\
White-lipped peccary Tayassu pecari & $345(16)$ \\
Caiman & $185(8)$ \\
Pig & $110(6)$ \\
Feral pig Sus scrofa scrofa & $5(1)$ \\
\hline
\end{tabular}

TABLE 2 Details of the 52 and 32 prey killed by female jaguars 1 and 2, respectively, after release (January 2017-December 2017) and, for comparison, the mean per cent of total prey killed by jaguars in an earlier study in the southern Pantanal.

\begin{tabular}{llll}
\hline Prey & $\begin{array}{l}\text { Female 1 } \\
\text { (\% of total) }\end{array}$ & $\begin{array}{l}\text { Female 2 } \\
\text { (\% of total) }\end{array}$ & $\begin{array}{l}\text { Mean \% of } \\
\text { kills (range) }\end{array}$ \\
\hline $\begin{array}{l}\text { Caiman } \\
\text { Capybara }\end{array}$ & $\begin{array}{c}1(61) \\
\text { White-lipped }\end{array}$ & $\begin{array}{c}18(56) \\
4(12)\end{array}$ & $\begin{array}{c}36(10-52) \\
\text { peccary }\end{array}$ \\
$\begin{array}{l}\text { Armadillo Dasypus } \\
\quad \text { novemcinctus }\end{array}$ & $1(2)$ & $3(10)$ & $30(0-57)$ \\
$\begin{array}{l}\text { Coati Nasua nasua } \\
\text { Raccoon Procyon }\end{array}$ & $5(10)$ & $2(6)$ & $2(0-15)$ \\
$\quad$ cancrivorus & & $1(3)$ & $1(0-4)$ \\
Crab eating fox & & $1(3)$ & $1(0-3)$ \\
$\quad$ Cerdocyon thous & & & $4(0-17)$ \\
$\begin{array}{l}\text { Giant anteater } \\
\text { Deer Mazama sp. }\end{array}$ & $2(4)$ & & $2(0-5)$ \\
Bird & $1(2)$ & & $1(0-3)$ \\
\hline
\end{tabular}

${ }^{1}$ From Cavalcanti \& Gese (2010).

(95\% CI 79.1-118.1) for jaguar 1, and $64.2 \mathrm{~km}^{2}$ (95\% CI 55.573.7) for jaguar 2 (Fig. 1). Both individuals anchored their home range around the enclosure and showed high spatial overlap with each other ( $85 \%$, 95\% CI 74-94\%; Fig. 1). The home ranges included areas with ecotourism and cattle ranching activities, areas with wild prey, and well-preserved natural vegetation. Directionality in movement paths, represented by the velocity autocorrelation timescale (h), were 0.45 (95\% CI $0.42-0.46$ ) and 0.45 (95\% CI 0.42-0.48) for jaguar 1 and 2, respectively. Mean distances travelled per day were 9.6 and $10.3 \mathrm{~km}$ for jaguar 1 and 2, respectively. Daily
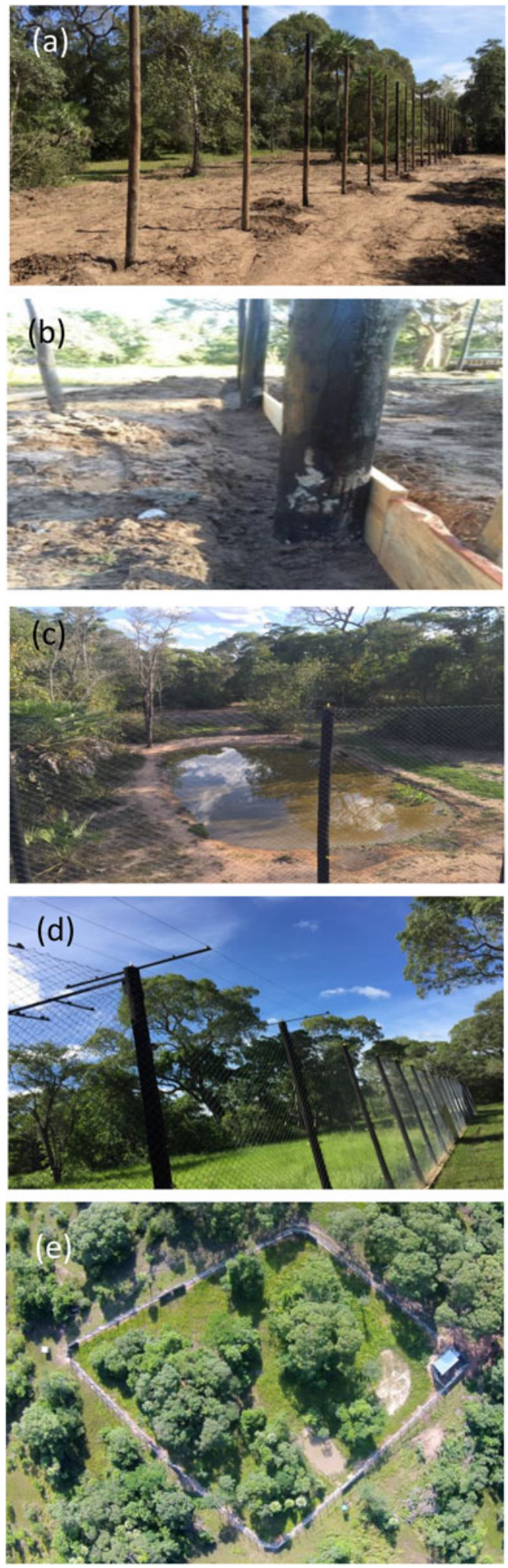

Plate 1 The 1 ha enclosure in the Caiman Ecological Refuge (Fig. 1): (a) $4.5 \mathrm{~m}$ high eucalyptus posts, $3 \mathrm{~m}$ apart; (b) $40 \mathrm{~cm}$ deep trench excavated around the perimeter of the enclosure and filled with cement, to prevent any animal digging into or out of the enclosure; (c) c. $2 \mathrm{~m}$ deep, $60 \mathrm{~m}^{2}$ pond; (d) galvanized wire perimeter fence of $2.2 \mathrm{~mm}$ gauge and $6 \times 6 \mathrm{~cm}$ mesh, with electric wires at 40,100 and $200 \mathrm{~cm}$, both inside and outside and on the top of the fence; (e) aerial view. 

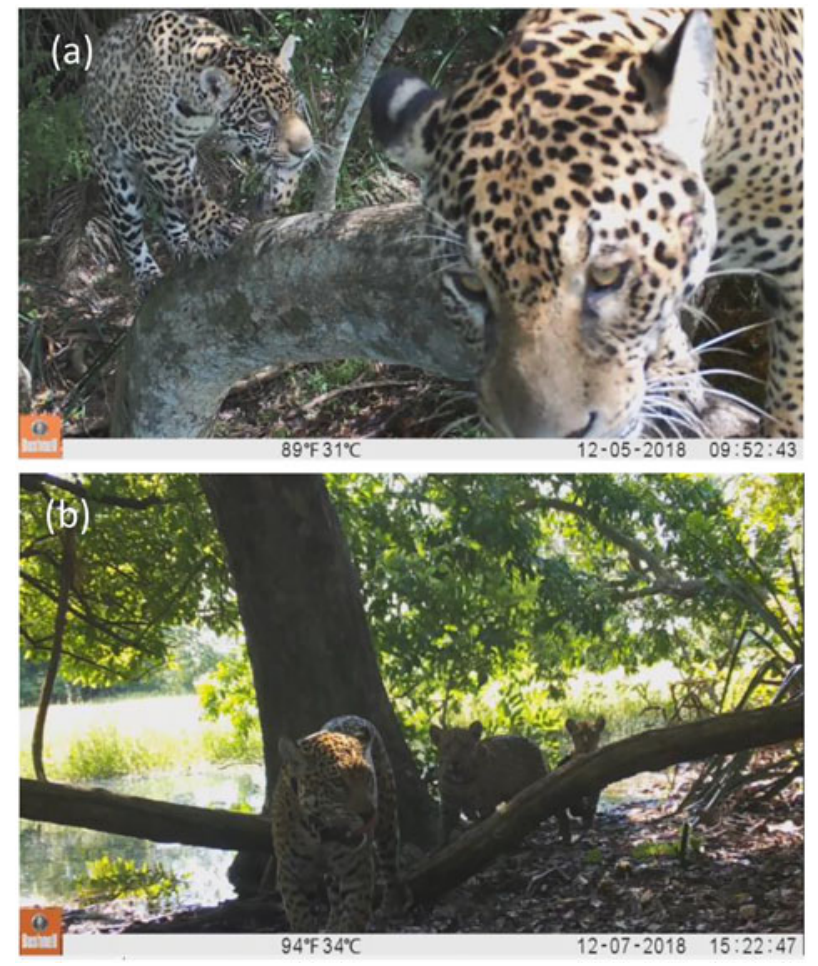

Plate 2 (a) Jaguar 1 with her 6-7 month old cub, photo-trapped in December 2018, and (b) Jaguar 2 and her two 4-5 month old cubs, photo-trapped in December 2018.

activity was similar to that previously reported for jaguars, with both individuals moving (hunting and transiting) during the night and resting during the day (Kanda et al., 2019). We identified 10 species preyed upon by the two jaguars (Table 2). Social interactions were observed between the two jaguars and nine other individual jaguars), including mating, fighting and paired movement. Jaguar 1 gave birth to a cub in c. June 2018 and jaguar 2 gave birth to two cubs in c. August 2018 (Plate 2).

The two jaguars established residence near the enclosure, with home ranges, and movement and activity patterns similar to those reported for free living individuals (Morato et al., 2016), and prey consumption similar to that recorded in a previous study in the same area (Cavalcanti \& Gese, 2010), including a high consumption of caimans. The exhibition of social interactions, and reproduction, indicate that the reintroduction was successful.

The main objective of a reintroduction is usually to reestablish or supplement an extinct or declining population (Cheyne, 2006). We released two individuals in an area where jaguars are not facing a high risk of extinction (Morato et al., 2013) and threats are low. Our intention was to evaluate a protocol that could be applied to other subpopulations across the species' range, and specifically for the Critically Endangered subpopulation of the Atlantic Forest (Morato et al., 2013). Despite the success of this reintroduction in the Pantanal we need to be cautious in using this tool for the species' long-term survival.
As a pre-condition for reintroduction, the highest priority must be to address the threats that are causing jaguar population declines. Firstly, some jaguar subpopulations are proximal to areas where people are active, potentially resulting in negative interactions. Jaguars involved in such interactions are often killed by members of the affected community (Inskip et al., 2013). In such areas, law enforcement to prevent killing of jaguars, and alleviation of negative interactions with ranchers, are required and should play a central role in planning any reintroduction (Caruso \& Pérez, 2013). Secondly, in areas that have undergone deforestation (Ribeiro et al., 2009) or defaunation (Jorge et al., 2013), it is important to evaluate habitat quality and prey availability before establishing a reintroduction programme. Thirdly, social interaction is a key component. The absence of intersexual territoriality (Crawshaw \& Quigley, 1991) suggests that reintroducing female jaguars is likely to increase the success of reintroductions in areas where male jaguars are present. Fourthly, jaguars tend to move in areas with which they are familiar, evidence of cognitive capacity and spatial memory (Kanda et al., 2019), and therefore building enclosures in the release area and keeping individuals there prior to release may facilitate acclimation. Fifthly, the cost of reintroduction needs to be compared to alternative strategies. The total cost for reintroducing the two female jaguars was c. USD 111,49o, without considering the costs of previous studies of the species' behaviour in the same area. This reintroduction was in an area where spatial ecology, habitat and prey preferences were known (Cavalcanti \& Gese, 2009, 2010; Morato et al., 2016). In the Atlantic Forest on the Argentina-Brazil border the main strategy for the southernmost jaguar subpopulation was to reduce persecution and poaching by means of education and law enforcement. The annual cost of the programme was c. USD 97,000 and after 10 years the jaguar population increased from an estimated 50 to 90 individuals (Paviolo et al., 2016).

In conclusion, reintroduction can be an important tool in areas where the jaguar population is in severe decline. It is the only option where the species has been extirpated and the management goal is reintroduction, residency and recovery. This study defines some of the practices and parameters that led to a successful outcome in the Pantanal.

Acknowledgements We thank Centro de Reabilitação de Animais Silvestres de Campo Grande and Instituto de Meio Ambiente de Mato Grosso do Sul for rescuing the jaguars; Mantenedor Santa Rosa for hosting and caring for them; Caiman Ecological Refuge for allowing us to build the training facility and release the jaguars on their property; Alexandre Bossi, Camila Martins, Écio Silva, Fernando Von Zuben, Márcia Reed, Pedro Lacerda Camargo, Raphael Klabin, Robert Kozmann Jr, and Roberto Klabin and Instituto SOS Pantanal for their support; Log Materials and Bushnell Corporation for donating camera traps; and Tetrapak for donating materials to build the enclosure. 
Author contributions Study design: RLG-M, LS, LR, PT, MH, RCdP, RGM; fieldwork: LS, LR, CEF, JAMJ, MH, RCdP; data analysis, writing: RLG-M, LS, RGM; revision: LS, LR, CEF, JAMJ, PT, MH, RCdP.

Conflicts of interest The authors have no relationship with Log Materials, Bushnell Corporation or Tetrapak, who donated equipment for research purposes only.

Ethical standards All research protocols were approved by Instituto Chico Mendes de Conservação da Biodiversidade and Sistema de Autorização e Informação em Biodiversidade (licenses 46508, 47979, 52734), and the research followed guidelines approved by the American Society of Mammalogists, and otherwise abided by the Oryx guidelines on ethical standards.

\section{References}

Breitenmoser, U., Breitenmoser-Wursten, C., Carbyn, L.N. \& FUNK, S. (2001) Assessment of carnivore reintroductions. In Carnivore Conservation (eds J.L. Gittleman, S.M. Funk, D. MacDonald \& R.K. Wayne), pp. 241-281. Cambridge University Press, Cambridge, UK.

Calabrese, J.M., Fleming, C.H. \& Gurarie, E. (2016) Ctmm: an $R$ package for analyzing animal relocation data as a continuous-time stochastic process. Methods in Ecology and Evolution, 7, 1124-1132.

Caruso, F. \& Pérez, I.J. (2013) Tourism, local pride, and attitudes towards the reintroduction of a large predator, the jaguar Panthera onca in Corrientes, Argentina. Endangered Species Research, 21, 263-272.

Cavalcanti, S.M.C. \& Gese, E.M. (2009) Spatial ecology and social interactions of jaguars (Panthera onca) in the Southern Pantanal, Brazil. Journal of Mammalogy, 91, 722-736.

Cavalcanti, S.M.C. \& Gese, E.M. (2010) Kill rates and predation patterns of jaguars (Panthera onca) in the southern Pantanal, Brazil. Journal of Mammalogy, 90, 935-945.

Cheyne, S.M. (2006) Wildlife reintroduction: considerations of habitat quality at the release site. BMC Ecology, 6, 5 .

Crawshaw, P.G. \& Quigley, H.B. (1991) Jaguar spacing, activity and habitat use in a seasonally flooded environment in Brazil. Journal of Zoology, 223, 357-370.

De la Torre, J.A., González-Maya, J.F., Zarza, H. \& Ceballos, G. (2017) The jaguar's spots are darker than they appear: assessing the global conservation status of the jaguar Panthera onca. Oryx, 52, 300-315.

de Paula, R.C., Cavalcanti, S.M.C. \& Morato, R.G. (2012) Plano de Ação para a Conservação da Onça Pintada. Instituto Chico Mendes de Conservação da Biodiversidade, Brasília, Brazil.

Fleming, C..H., Fagan, W.F., Mueller, T., Olson, K.A., Leimgruber, P. \& Calabrese, J.M. (2015) Rigorous home range estimation with movement data: a new autocorrelated kernel density estimator. Ecology, 96, 1182-1188.
Galetti, M., Eizirik, E., Beisiegel, B., Ferraz, K., Cavalcanti, S., Srbek-Araujo, A.C. et al. (2013) Atlantic rainforest's jaguars in decline. Science, 342, 930.

Inskip, C., Ridout, M., Fahad, Z., Tully, R., Barlow, A., Barlow, C.G. et al. (2013) Human-tiger conflict in context: risks to lives and livelihoods in the Bangladesh sundarbans. Human Ecology, $41,169-186$.

IUCN (2013) Guidelines for Reintroductions and other Conservation Translocations. IUCN, Gland, Switzerland. issg.org/pdf/ publications/RSG_ISSG-Reintroduction-Guidelines-2013.pdf [accessed 8 July 2020].

Jorge, M.L.S.P., Galetti, M., Ribeiro, M.C., Ferraz, K.M.P.M.B. (2013) Mammal defaunation as surrogate of trophic cascades in a biodiversity hotspot. Biological Conservation, 163, 49-57.

Kanda, C., Oliveira-Santos, L.G., Morato, R.G., De Paula, R.C., Rampim, L., SARtorello, L. et al. (2019) Unexpected spatial overlap in a solitary carnivore is revealed by simultaneous GPS-tracking of jaguars (Panthera onca). Journal of Zoology, 308, 66-74.

Morato, R.G., Beisiegel, B.M., Ramalho, E.E. \& Boulhosa, R.L.P. (2013) Avaliação de risco de extinção de onça pintada Panthera onca (Linnaeus, 1758) no Brasil. Biodiversidade Brasileira, 1, 122-132.

Morato, R.G., Stabach, J.A., Fleming, C.H., Calabrese, J.M., de PAULA, R.C. et al. (2016) Space use and movement of a neotropical top predator: the Endangered jaguar. PLOS ONE, 11, eo168176.

Paviolo, A., De Angelo, C., Ferraz, K.M.P.M.B., Morato, R.G., PARDO, J.M. et al. (2016) A biodiversity hotspot losing its top predator: the challenge of jaguar conservation in the Atlantic Forest of South America. Scientific Reports, 6, 37147.

Perilli, M.L.L., Lima, F., Rodrigues, F.H.G. \& Cavalcanti, S.M.C. (2016) Can scat analysis describe the feeding habits of big cats? A case study with jaguars (Panthera onca) in the Southern Pantanal, Brazil. PLOS ONE, 11, eo151814.

R Core TeAm (2018) R: A language and environment for statistical computing. R Foundation for Statistical Computing, Vienna, Austria. R-project.org [accessed 8 July 2020].

Rabinowitz, A. \& Nottingham, B.G. (1986) Ecology and behavior of the jaguar (Panthera onca) in Belize. Journal of Zoology, 21, 149-159.

Rampim, L.E, Sartorello, L.R., Fragoso, C.E., Haberfeld, M. \& Devlin, A.L. (2020) Antagonistic interactions between predator and prey: mobbing of jaguars by white-lipped peccaries. Acta Ethologica, 23, 45-48.

Ribeiro, M.C., Metzger, J.P., Martensen, A.C., Ponzoni, F.J. \& Hirota, M.M. (2009) The Atlantic Rainforest: how much is left, and how is the remaining forest distributed? Implications for conservation. Biological Conservation, 142, 1141-1153.

Soisalo, M.K. \& Cavalcanti, S.M.C. (2006). Estimating the density of a jaguar population in the Brazilian Pantanal using camera-traps and capture-recapture sampling in combination with GPS radio-telemetry. Biological Conservation, 129, 487-96. 